\title{
Study of the peri-operative mortality in trochanteric fractures in elderly patients (60 years and above) visiting department of orthopedics at Dr. RPGMC Tanda
}

\author{
Sarvesh Kumar Singh, Bhanu Awasthi, Devinder Kumar, Sunil Rana, \\ Atul Singh, Sunny Dua*
}

Department of Orthopedics, Dr. RPGMC, Kangra, Tanda, Himachal Pradesh, India

Received: 27 January 2021

Revised: 11 February 2021

Accepted: 16 February 2021

*Correspondence:
Dr. Sunny Dua,
E-mail: sunydua64@gmail.com

Copyright: ( the author(s), publisher and licensee Medip Academy. This is an open-access article distributed under the terms of the Creative Commons Attribution Non-Commercial License, which permits unrestricted non-commercial use, distribution, and reproduction in any medium, provided the original work is properly cited.

\begin{abstract}
Background: In elderly, trochanteric fractures are frequent and typically result from mild to moderate trauma in osteoporotic bones while in young adults these fractures are generally due to high energy trauma such as road side accidents.

Methods: The present study was conducted in elderly patients with trochanteric fractures (age 60 years and above) presenting to the department of orthopedics, Dr. RPGMC Kangra at Tanda. All cases presenting to the department and fulfilling the inclusion criteria were studied for three months period from the day of surgery. All cases fulfilling the inclusion criteria who were operated over the period of one year from the date of start of study were included.

Results: Our study observed that out of 176 patients, $10.23 \%(n=18 / 176)$ patients could not survive within 90 days of surgery while $89.8 \%(n=158 / 176)$ patients survived. Perioperative mortality was $10.23 \%$.

Conclusions: In our study, peri-operative mortality is lower than reported earlier. We also found that perioperative mortality was influenced by older age.
\end{abstract}

Keywords: Mortality, Trochanteric fracture, Elderly

\section{INTRODUCTION}

Perioperative mortality is defined as the time interval from the day of surgery to three months post-operatively.

Moreover, since trochanteric fracture prevalence increases exponentially with age, as population age and longevity increasing worldwide, these injuries are likely to occurs at accelerated rates. This is important because among those who sustain a trochanteric fracture injury and survive, an increasing number continue to experience various degrees of subsequent disability including a high risk for falls and further injury likewise. Hip fractures remain a persistent cause of excessive morbidity, reduced life quality and premature mortality amongelderly. ${ }^{1}$

In elderly, trochanteric fractures are frequent and typically result from mild to moderate trauma in osteoporotic bones while in young adults these fractures are generally due to high energy trauma such as road side accidents. This is mainly because elderly people are unable to dissipate energy as compared to the young person and diminished ambulatory speed. Their protective responses are also diminished because of slow reaction time, weakness, disorientation and the side effect ofmedication. ${ }^{2}$

The trochanteric fractures pose a number of management dilemmas depending on the age, sex, nutritional status, 
comorbidities, status of the bones and type of fractures. Advanced age and associated comorbidities are two decisive factors of mortality secondary to trochanteric fracture.

In this study we determine peri-operative mortality in trochanteric fractures in elderly patients (60 years and above) visiting department of orthopedics at Dr. RPGMC Tanda.

\section{METHODS}

Study design was hospital based prospective study. The present study was conducted in elderly patients with trochanteric fractures (age 60 years and above) presenting to department of orthopedics, Dr. RPGMC Kangra at Tanda.

All cases presenting to the department and fulfilling the inclusion criteria were studied for three months period from the day of surgery. All cases fulfilling the inclusion criteria who were operated over the period of one year (June 2018 to July 2019) from the date of start of study were included.

Sample technique used was simple random sampling and sample size included all patients reported during study duration.

\section{Ethical consideration}

The study was initiated following approval from institutional ethics committee (IEC). The patients were given the right to abstain from participation in the study or to withdraw at any time of the study without reprisal.

Inclusion criteria included all patients of trochanteric fracture 60 years and above, all patients meeting the exclusion criteria were excluded from the study.

Exclusion criteria excluded concomitant trauma involving other systems, associated fracture of the pelvis, bilateral hip fracture, pathological fracture and did not give consent to participate in the study.

After a detailed history, patients were clinically evaluated at the time of admission. The demographic data of the patients such as age, sex, pre-existing co-morbidities, bed sores, type of fracture and degree of osteoporosis were recorded.

\section{Statistical analysis}

The data were presented as frequency, percentages, mean $\pm \mathrm{SD}$, median and inter quartile range wherever applicable. Normally it of distribution was evaluated using ShapiroWilk test. Student t test was used to compare continuous variables with normal distribution. Chi-square test was used using categorical variables. Skewed data between 2 groups were compared using Mann Whitney U test. P value $<0.05$ was considered significant. Statistical analysis was performed using SPSS v21.

\section{RESULTS}

The present study was aimed to evaluate peri-operative mortality in trochanteric fractures in elderly patients (60 years and above) in department of orthopedics, Dr RPGMC Kangra at Tanda over the period of one year. A total of 176 patients with trochanteric fractures were included in the study. Results of the study have been described below:

Table 1: Perioperative mortality $(n=176)$.

\begin{tabular}{|lll|}
\hline $\begin{array}{l}\text { Perioperative } \\
\text { mortality }\end{array}$ & Frequency & $\begin{array}{l}\text { Percentage } \\
(\%)\end{array}$ \\
\hline Yes & 18 & 10.2 \\
\hline No & 158 & 89.8 \\
\hline Total & 176 & 100.0 \\
\hline
\end{tabular}

Our study observed that out of 176 patients, $10.23 \%$ $(n=18 / 176)$ patients could not survive within 90 days of surgery while $89.8 \% \quad(n=158 / 176)$ patients survived. Perioperative mortality was 10.23 .

Table 2: General characteristics of the study population $(n=176)$.

\begin{tabular}{|c|c|c|c|c|}
\hline Variables & Age (years) & Group A (n=18) & Group B $(n=158)$ & P value \\
\hline \multirow{3}{*}{ Age (year) } & Mean \pm SD & $85.44 \pm 7.86$ & $74.65 \pm 9.56$ & \multirow{3}{*}{$<0.0001 \# *$} \\
\hline & Median & 89.0 & 75.0 & \\
\hline & IQR & $79.75,90.0$ & $65.0,82.0$ & \\
\hline \multirow{2}{*}{ Sex } & Male & 7 & 73 & \multirow{2}{*}{$0.733^{\# \#}$} \\
\hline & Female & 11 & 85 & \\
\hline \multirow{2}{*}{ Residence } & Rural & 18 & 155 & \multirow{2}{*}{-} \\
\hline & Urban & 0 & 3 & \\
\hline Kuppuswamy scale & $\begin{array}{l}\text { Upper middle } \\
\text { class }\end{array}$ & 0 & 3 & - \\
\hline \multirow{3}{*}{ Udai Pareekh scale } & Upper & 0 & 0 & \multirow{3}{*}{-} \\
\hline & Upper middle & 6 & 34 & \\
\hline & Middle & 9 & 82 & \\
\hline
\end{tabular}




\section{DISCUSSION}

The present study was conducted in patients with trochanteric fractures (age 60 years and above) presenting to the department of orthopedics, Dr. RPGMC Kangra at Tanda.

Excess mortality after hip fracture may be linked to complications following the fracture, such as pulmonary embolism, infections, and heart failure. Factors associated with the risk of falling and sustaining osteoporotic fractures may also be responsible for the excess mortality. Excess mortality after fracture may be due to the individual characteristics of the person sustaining the hip fracture; e.g., low-bone density is associated with increased nontrauma mortality, even without fractures.

Although several studies report excess mortality in hip fracture patients compared to controls, the issue remains under-recognized in many countries like India. ${ }^{3}$ Furthermore, peri-operative mortality after hip fracture has not been extensively investigated in India. ${ }^{4}$

Our finding of a higher number of fractures among females is in line with most of the previous studies. ${ }^{5}$ The high age of the patients reflects that there is an increased risk to fall with advanced age, and as these patients often are frail with poor bone-quality there is an increased risk for suffering from a hip fracture even after a low energy fall. Being female puts you at risk of developing osteoporosis and broken bones. In a study, the 10-year risk of hip fracture was $0.3 \%$ for a 50 -year-old woman and $8.7 \%$ at the age of 80 years. $^{6}$ In addition to increased skeletal fragility observed with aging, the risk of falling also rises with advancing age.

\section{Limitations}

Limitations of the study were less time duration and study were single center study.

\section{CONCLUSION}

In our study, peri-operative mortality is lower than reported earlier studies. We also found that perioperative mortality was influenced by older age. Age was a risk factor for perioperative mortality. This warrant better management of co-morbid conditions and peri-operative care of elderly patients as a strategy to reduce posttraumatic peri-operative mortality in elderly patients with trochanteric fractures.
Funding: No funding sources

Conflict of interest: None declared

Ethical approval: The study was approved by the institutional ethics committee

\section{REFERENCES}

1. Marks R. Physical activity and hip fracture disability: a review. J Aging Res. 2011;3:1-7.

2. Babhulkar S. Management of trochanteric Fractures. Indian J Orthop. 2006;40:210-18.

3. Zhao F, Wang X, Dou Y, Wang H, Zhang Y. Analysis of risk factors for perioperative mortality in elderly patients with intertrochanteric fracture. Eur J Orthop Surg Traumatol. 2019;29:59-63.

4. Åhman R, Siverhall PF, Snygg J, Fredrikson M, Enlund G, Björnström K, Chew MS. Determinants of mortality after hip fracture surgery in Sweden: a registry- based retrospective cohort study. Sci Rep. 2018;8:15695.

5. Kawai M, Tanji A, Nishijima T, Tateyama K, Yoda $\mathrm{Y}$, Iizuka A et al. Association between time to surgery and 90-day mortality after hip fracture: A retrospective cohort study of 1734 cases. J Orthop Sci. 2018;23:987-91.

6. Van Staa TP, Dennison EM, Leufkens HG, Cooper C. Epidemiology of fractures in England and Wales. Bone. 2001;29:517-22.

7. Dhanwal DK, Siwach R, Dixit V, Mithal A, Jameson $\mathrm{K}$, Cooper $\mathrm{C}$. Incidence of hip fracture in Rohtak district, North India. Arch Osteoporos. 2013;8:135.

8. Johnell O, Kanis JA, Oden A, Johansson H, De Laet C, Delmas P, et al. Predictive value of BMD for hip and other fractures. $\mathrm{J}$ Bone Mineral Res. 2005;20:1185-94.

9. Mnif H, Koubaa M, Zrig M, Trabelsi R, Abid A. Elderly patient's mortality and morbidity following trochanteric fracture. A hundred cases prospective study. Orthop Traumatol Surg Res. 2009;95:505-10.

10. Keene GS, Parker MJ, Pryor GA. Mortality and morbidity after hip fractures. BMJ. 1993;307:124850 .

Cite this article as: Singh SK, Awasthi B, Kumar D, Rana S, Singh A, Dua S. Study of the perioperative mortality in trochanteric fractures in elderly patients (60 years and above) visiting department of orthopaedics at Dr. RPGMC Tanda. Int J Res Orthop 2021;7:325-7. 